\title{
Studies on Heterogeneous Lipopolysaccharide Fractions of Vibrio cholerae 569B
}

\author{
By DEBOPAM CHAKRABARTI $\dagger$ AND ANADI N. CHATTERJEE*† \\ Department of Microbiology, Bose Institute, Calcutta 700 009, India
}

(Received 25 January 1984; revised 21 March 1984)

\begin{abstract}
By SDS-PAGE or gel filtration on Sephadex G-25, lipopolysaccharide (LPS) isolated from Vibrio cholerae 569B (Inaba) can be separated into two distinct fractions, one corresponding to smooth LPS and the other to rough LPS. Pulse-labelling of LPS with $\left[{ }^{14} \mathrm{C}\right]$ glucose showed that the rough form is synthesized first followed by the biosynthesis of the smooth form. A preferential release of the smooth LPS of $V$. cholerae 569B was also detected during normal growth of cells.
\end{abstract}

\section{INTRODUCTION}

Heterogeneity of LPS has been demonstrated in different Gram-negative bacteria (Alphen $e t$ al., 1983; Goldman \& Leive, 1980; Jann et al., 1975; Koeltzow \& Conrad, 1971; Palva \& Mäkelä, 1980). The heterogeneous LPS fractions have been shown to be released in different proportions in the culture supernate when the organisms are grown in a liquid medium (Munford et al., 1980). We have found that the LPS of Vibrio cholerae 569B can be resolved into smooth and rough LPS forms upon gel electrophoresis. In the present paper we report on the rates of incorporation of radioactive glucose into the two LPS fractions and their release into the culture medium.

\section{METHODS}

Bacterial strain and growth conditions. Vibrio cholerae 569B (Inaba serotype) was obtained from the National Institute of Cholera and Enteric Diseases, Calcutta, India. It was grown at $37^{\circ} \mathrm{C}$ in a gyratory shaker (New Brunswick Scientific Co.) in a medium (BP) containing $1 \%(w / v)$ beef extract (Centron Laboratories, India), $1 \%$ (w/v) peptone (Centron) and $1 \%(\mathrm{w} / \mathrm{v}) \mathrm{NaCl}, \mathrm{pH} 8 \cdot 0$.

Pulse-labelling of LPS. Exponentially growing 569B cells were pulse-labelled with $1.0 \mu \mathrm{Ci}\left[\mathrm{U}-{ }^{14} \mathrm{C}\right]-\mathrm{D}-$ glucose $\mathrm{ml}^{-1}$ [specific activity $114 \mu \mathrm{Ci} \mu \mathrm{mol}^{-1}\left(4 \cdot 22 \mathrm{MBq}^{-1} \mathrm{~mol}^{-1}\right)$; Bhaba Atomic Research Centre, India] in BP medium containing $1.4 \times 10^{-6} \mathrm{M}$-non-radioactive glucose for 15,30 or $60 \mathrm{~s}$. At specified time intervals incorporation was stopped by adding an equal volume of prewarmed $90 \%(\mathrm{w} / \mathrm{v})$ phenol to the culture and the labelled LPS was isolated by the phenol/water extraction method (Westphal \& Jann, 1965).

Measurement of LPS release. Labelled LPS was prepared by adding $0.5 \mu \mathrm{Ci}\left[\mathrm{U}^{-14} \mathrm{C}\right.$-D-glucose $\mathrm{ml}^{-1}$ (specific activity $114 \mu \mathrm{Ci} \mu \mathrm{mol}^{-1}$ ) to an exponentially growing culture in BP medium containing $10^{-4} \mathrm{M}$-non-radioactive glucose and the incorporation was continued for $90 \mathrm{~min}$. Cells were then harvested $\left(6000 \mathrm{~g}, 10 \mathrm{~min}\right.$ at $\left.25^{\circ} \mathrm{C}\right)$, washed and re-suspended in prewarmed BP medium containing $1.6 \times 10^{-2} \mathrm{M}$-non-radioactive glucose to an $\mathrm{OD}_{585}$ of $0 \cdot 15$. Cells were allowed to grow with shaking in the non-radioactive medium for $180 \mathrm{~min}$. The culture was then centrifuged $\left(6000 \mathrm{~g}, 10 \mathrm{~min}\right.$ at $\left.25^{\circ} \mathrm{C}\right)$ and the labelled LPS released in the supernate was isolated by phenol/water extraction (Westphal \& Jann, 1965).

$S D S$-PAGE. LPS was solubilized in sample buffer (Jann et al., 1975) and electrophoresed (5.6\% gel) at $5 \mathrm{~mA}$ $\mathrm{gel}^{-1}$ for $3.5 \mathrm{~h}$. LPS bands on the gel were visualized by periodate-Schiff staining (Stewart-Tull, 1965; Dirienzo et al., 1978).

$†$ Present address: Research and Development Division, Organon (India) Ltd, 182 A. J. C. Bose Road, Calcutta 700014 , India. 
Determination of radioactivity in gel slices. After electrophoresis the entire gel was cut into $2 \mathrm{~mm}$ thick slices, which were put into scintillation vials containing $0.5 \mathrm{ml} 1 \%(\mathrm{w} / \mathrm{v}) \mathrm{SDS}$ and shaken for about $15 \mathrm{~h}$ at $37^{\circ} \mathrm{C}$. Triton X-100-based scintillation fluid (Patterson \& Greene, 1965) $(5.0 \mathrm{ml})$ was added to each vial; the vials were kept in the dark for about $12 \mathrm{~h}$ before measuring the radioactivity in a Beckman LS-100C scintillation counter. The counting efficiency of ${ }^{1+} \mathrm{C}$-labelled gels was about $50 \%$.

\section{RESULTS AND DISCUSSION}

\section{Incorporation of radioactive label in the heterogeneous LPS fractions}

The LPS isolated from $V$. cholerae 569B can be separated into two bands (staining with periodate-Schiff reagent) in $5.6 \%$ gels with a relative mobility $\left(R_{\mathrm{m}}\right)$ of 0.6 (LPS I) and 0.88 (LPS II), respectively. Such heterogeneity of LPS has been demonstrated in Escherichia coli (Alphen $e t$ al., 1983; Goldman \& Leive, 1980; McIntire et al., 1969; Morrison \& Leive, 1975), Salmonella (Dirienzo et al., 1978; Goldman \& Leive, 1980; Palva \& Mäkelä, 1980; Ryan \& Conrad, 1974), Citrobacter (Jann et al., 1975), Aerobacter aerogenes (Koeltzow \& Conrad, 1971) and Alteromonas haloplanktis (Dirienzo et al., 1978). Chemical analysis of these LPS fractions indicated that LPS I corresponds to the smooth form of the LPS molecule containing both the core region and the Oantigenic chain while LPS II corresponds to the rough form containing only the core oligosaccharide. The polysaccharide moiety, obtained by hydrolysis of LPS by treatment with $1 \%(\mathrm{v} / \mathrm{v})$ acetic acid for $150 \mathrm{~min}$ at $100^{\circ} \mathrm{C}$, resolved into three peaks on Sephadex G-25 filtration. The first two peaks were polysaccharide in nature while the third peak contained only monomeric fructose. The composition and molar ratios of the monosaccharide present in the two polysaccharide peaks were very similar to the two LPS bands separated by SDS-PAGE. This has enabled us to make a tentative assignment of sugars characteristic of core region and $\mathrm{O}$ antigenic side chain. While heptose, glucose and fructose were present exclusively in the core oligosaccharide, perosamine and rhamnose were present only in the O-antigenic regions.

To investigate the pattern of biosynthesis of the smooth and rough forms of LPS present in $V$. cholerae $569 \mathrm{~B}$, cells in the exponential phase of growth were pulse-labelled for 15,30 and $60 \mathrm{~s}$ with $\left[{ }^{14} \mathrm{C}\right.$ ]glucose in the growth medium. The LPS extracted from cells labelled for $15 \mathrm{~s}$ had a peak of radioactivity corresponding to LPS II (Fig. 1). After $30 \mathrm{~s}$ of labelling the peak corresponding to LPS II increased while a small peak corresponding to LPS I was also detected. When the labelling was continued for $60 \mathrm{~s}$ the radioactivity recovered in the peaks corresponding to LPS I and LPS II was in the ratio $1 \cdot 5: 1 \cdot 0$. This is the normal distribution of total carbohydrate in the two LPS fractions as separated by SDS-PAGE. These results indicated that the label was first incorporated into the rough LPS II and the incorporation into the complete LPS I occurred subsequently. The labelling pattern is consistent with the known mechanism of LPS biosynthesis (Wright \& Tipper, 1979), in which lipid A linked core oligosaccharide and $\mathrm{O}$-side chain are synthesized independently and the complete LPS molecule is formed by the transfer of the complete $\mathrm{O}$-side chain to the lipid A linked core oligosaccharide.

\section{$S D S-P A G E$ profile of the LPS released during normal growth of $V$. cholerae $569 B$}

Gram-negative bacteria growing in liquid media release fragments of outer membrane (Hoekstra et al., 1976; Rothfield \& Pearlman-Kothencz, 1969). Electron microscopic studies with $V$. cholerae cells also indicated formation of surface blebs which were released into the culture medium (Chatterjee \& Das, 1967; Chatterjee et al., 1974). Therefore it was of interest to determine if either of the two forms of LPS were preferentially released during growth of $V$. cholerae 569B. When $\left[{ }^{14} \mathrm{C}\right]$ glucose-labelled $V$. cholerae 569B cells were allowed to grow in a nonradioactive medium, most of the radioactivity recovered in the culture supernate was located in the LPS I fraction (Fig. 2). The ratio of total radioactivity in LPS I and LPS II was about $7 \cdot 3: 1 \cdot 0$. The same pattern was seen with cultures which were chased for $60 \mathrm{~min}$ and $120 \mathrm{~min}$ in the nonradioactive medium. This suggests a preferential release of smooth LPS molecules during growth. We have isolated a rough mutant strain (DBI6) from 569B whose LPS resolved into a single band corresponding to LPS II on SDS-PAGE. As would be expected, the excretion of LPS from this mutant strain in the culture medium was reduced significantly. This preferential 


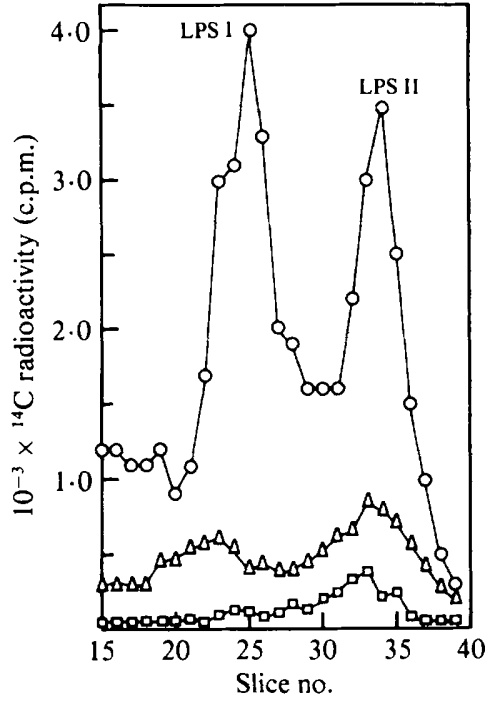

Fig. 1

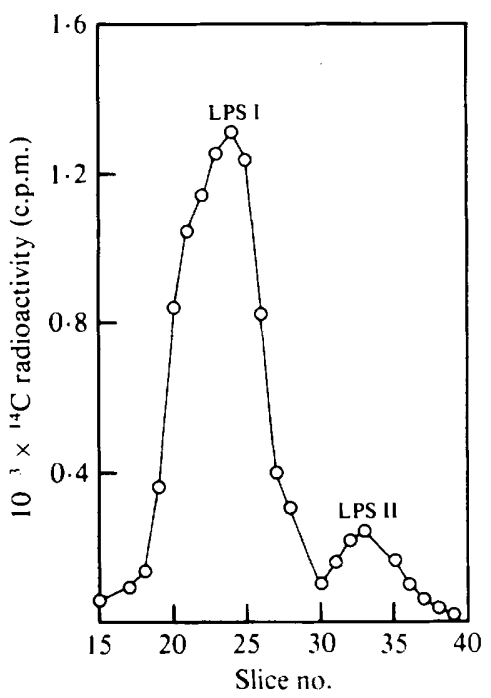

Fig. 2

Fig. 1. Kinetics of incorporation of radioactive label in LPS fractions. Cultures were pulse-labelled with $\left[{ }^{14} \mathrm{C}\right] \mathrm{glucose}$ and LPS was extracted by phenol/water and subjected to gel electrophoresis (see Methods). Gels were sliced $(2 \mathrm{~mm})$ and monitored for radioactivity. The origin is at the left-hand side. Time of pulse: $15 \mathrm{~s}(\square), 30 \mathrm{~s}(\triangle), 60 \mathrm{~s}(\mathrm{O})$.

Fig. 2. SDS-PAGE profile of LPS released in the culture medium. Exponentially growing $V$. cholerae 569B cells were labelled for $90 \mathrm{~min}$ with [ $\left.{ }^{14} \mathrm{C}\right]$ glucose (see Methods) and grown in non-labelled medium. The LPS released into the culture supernate was extracted and subjected to SDS-PAGE. The origin is at the left-hand side.

release of smooth LPS from $V$. cholerae 569B is in agreement with recent studies in Salmonella typhimurium (Munford et al., 1980) where LPS excreted in the culture supernate was predominantly of the smooth form.

This investigation was supported by a grant from the Department of Science and Technology, Government of India. One of us (D. C.) was a recipient of Lady Tata Memorial Trust senior research fellowship. We wish to thank S. Das and B. DeySarkar for their technical assistance.

\section{REFERENCES}

AlPhen, L. van, KEMPEN-DE Troye, F. van \& ZANEN, H. C. (1983). Immunological detection of heterogeneous $\mathrm{O}$-antigen containing lipopolysaccharides in E. coli. Journal of General Microbiology 129, 191-198.

Chatterjee, S. N. \& Das, J. (1967). Electron microscopic observations on the excretion of cell-wall material by Vibrio cholerae. Journal of General Microbiology 49, 1-11.

Chatterjee, S. N., Adhikari, P. C., Maiti, M., RaychaudhuRI, C. \& SUR, P (1974). Growth of Vibrio cholerae cells: biochemical and electron microscopic study. Indian Journal of Experimental Biology 12, 35-45.

Dirienzo, J. M., Deneke, C. F. \& Macleod, R. A. (1978). Heterogeneity and distribution of lipopolysaccharide in the cell wall of a Gram-negative marine bacterium. Journal of Bacteriology 136, 148157.
Goldman, R. C. \& Leive, L. (1980). Heterogeneity of antigenic-side-chain length in lipopolysaccharide from Escherichia coli $\mathrm{O} 111$ and Salmonella typhimurium LT2. European Journal of Biochemistry 107, 145153.

Hoekstra, D., LAaN, J. W. VAN Der, Leu, L. DE \& WITHOLT, B. (1976). Release of outer membrane fragments from normally growing Escherichia coli. Biochimica et biophysica acta 455, 889-899.

J ANN, B., RESKE, K. \& JANN, K. (1975). Heterogeneity of lipopolysaccharides. Analysis of polysaccharide chain lengths by sodium dodecyl sulphate-polyacrylamide gel electrophoresis. European Journal of Biochemistry 60, 239-246.

Koeltzow, D. \& ConRad, H. (1971). Structural heterogeneity in the lipopolysaccharide of Aerobacter aerogenes NCTC 243. Biochemistry 10, 214224. 
Mcintire, F. C., Barlow, G. H., Sievert, H. W., FINLEY, R. A. \& Yoo, A. L. (1969). Studies on a lipopolysaccharide from Escherichia coli. Heterogeneity and mechanism of reversible inactivation by sodium deoxycholate. Biochemistry 8, 4063-4067.

Morrison, D. \& LeIVE, L. (1975). Fractions of lipopolysaccharide from Escherichia coli O111:B4 prepared by two extraction procedures. Journal of Biological Chemistry 250, 2911-2919.

Munford, R. S., Hull, C. L. \& Rick, P. D. (1980). Size heterogeneity of Salmonella typhimurium lipopolysaccharide in outer membranes and culture supernatant membrane fragments. Journal of Bacteriology 144, 630-640.

Palva, T. \& MÄKelÄ, P. H. (1980). Lipopolysaccharide heterogeneity in Salmonella typhimurium analyzed by sodium dodecyl sulphate/polyacrylamide gel electrophoresis. European Journal of Biochemistry 107, 137-143.

Patterson, M. S. \& Greene, R. C. (1965). Measurement of low energy beta-emitters in aqueous solution by liquid scintillation counting of emulsions. Analytical Chemistry 37, 854-857.

Rothfield, L. \& PeARlman-KothenCZ, M. (1969). Synthesis and assembly of bacterial membrane components. A lipopolysaccharide-phospholipidprotein complex excreted by living bacteria. Journal of Molecular Biology 44, 477-492.

RYAN, J. M. \& ConRAD, H. E. (1974). Structural heterogeneity in the lipopolysaccharide of Salmonella newington. Archives of Biochemistry and Biophysics 162, 530-535.

Stewart-Tull, D. E. S. (1965). A modified PAS staining technique for polysaccharide in gels. Immunology 8, 221-222.

WeStPhal, O. \& JANN, K. (1965). Bacterial lipopolysaccharides. Extraction with phenol-water and further applications of the procedure. Methods in Carbohydrate Chemistry 5, 83-91.

WRIGHT, A. \& TIPPER, D. J. (1979). The outer membrane of Gram-negative bacteria. In The Bacteria, vol. 7, pp. 427-485. Edited by J. R. Sokatch \& L. N. Ornston. New York: Academic Press. 